\title{
E. T. A. Hoffmann: tradução da música para a forma literária
}

\author{
Maria Aparecida Barbosa
}

Ernst Theodor Wilhelm Hoffmann (1776-1822) é conhecido no Brasil, sobretudo, através do conto "O Homem da Areia", que foi objeto de estudo no ensaio "O Estranho" (Das Unheimliche), do psicanalista Sigmund Freud. Seu nome está geralmente associado à literatura fantástica. Mas é importante destacar que ele legou também uma relevante contribuição como compositor - sua ópera Undine alcançou grande sucesso de crítica e de público no Königliches Schauspielhaus (Teatro Real) de Berlim, em 1816 -, e também como crítico musical - seus ensaios foram, inicialmente, divulgados através do Allgemeine Musikalische Zeitung (Jornal de Música), entre 1809 e 1816.

Ao começar a escrever suas primeiras composições musicais, Hoffmann passou a substituir seu terceiro prenome por Amadeus, uma homenagem ao compositor que tanto admirava, o austríaco Wolfgang Amadeus Mozart (1756-1791). Contudo, sua ambição artística foi frustrada logo no início, pois, para manter a tradição da família, o jovem deveria seguir a carreira jurídica. Hoffmann chegou a ocupar, após 1821, um cargo na mais elevada instância do poder judiciário de Berlim, como jurisconsulto do Supremo Senado de Apelação Judicial. Por outro lado, porém, 
BARBOSA, Maria Aparecida. E. T. A. Hoffmann: tradução da música para a forma...

ainda alimentava o sonho de tornar-se compositor, o que explicaria a dedicação e o afinco com que estudava música. Então, de fato, ele viveu sempre dividido entre as obrigações burguesas e a aspiração artística.

Embora tenha sido também um habilidoso caricaturista e profundo conhecedor da arte pictórica, Hoffmann sempre manifestou preferência pela arte musical. $O$ certo é que, no final das contas, ele acabou se tornando conhecido, como sabemos, por meio de uma outra forma de expressão artística: a literatura.

A influência da música nos textos que começa a escrever e a publicar é evidente nos temas, no movimento das figuras, nas antropomorfoses, nas graduais transformações dos cenários, no ritmo. Nesse sentido, Hoffmann deixou um documento elucidativo sobre a forma como esquematizava uma narrativa escrita. Em 24.03.1814, numa carta ao editor, ele explica como imaginava o romance Os Elixires do Diabo: o início da obra seria um grave sostenuto, em seguida haveria um andante sostenuto e piano e, finalmente, allegro forte (WITTKOP-MÉNARDEAU, p. 24).

Sobre seu conto "Princesa Brambilla - um capriccio segundo Jakob Callot, de E. T. A. Hoffmann, com 8 ilustrações segundo folhas originais de Callot", o próprio autor esclarece: "musicalmente, eu diria que falta uma passagem de um tom para o outro, de forma que o novo acorde bate sem as necessárias preliminares. De fato, pode-se dizer que o capriccio se inicia com uma dissonância insolúvel" (WITTKOP-MÉNARDEAU, p. 24). Lembrando que capricho é a imprecisa denominação para uma peça de fantasia em prosa, normalmente apenas esboçada, e, simultaneamente, um atributo da música cuja forma, estrutura e movimento variam livremente.

Como afirmei, antes de tudo, Hoffmann era músico.

Essa circunstância foi fundamental para o surgimento do seu mais bem elaborado personagem segundo a crítica, o compositor 
Johann Kreisler. Hoffmann descrevia essa figura, protagonista do romance A Visão de Mundo do Gato Murr, como um espírito excitado, desprovido da fleuma e do equilíbrio necessários à criação. Ao personagem Kreisler, Hoffmann atribuiu a escritura das 13 "Kreisleriana", ensaios curtos, nos quais o regente de orquestra e compositor expressou suas críticas, suas concepções estéticas, não desprovidas, todavia, de uma forte dose de ironia, inclusive com os próprios sentimentos e idéias.

Para Hoffmann, a música expressava idéias e sentimentos, como uma "linguagem do coração". Por isso, o mistério da arte musical não era deste mundo; pois na natureza não se poderia encontrar protótipos para o músico, assim como há para o pintor ou o escultor. Numa língua divina, a música fala de um lugar distante e leva consigo o ouvinte ao "reino espiritual do infinito" (HOFFMANN: Vol. 1, p. 39). A capacidade de conceber melodias, ele comparou ao conhecimento da essência do universo; à música, ele se referiu como "sânscrito da natureza expressa em tons" (in Tönen ausgesprochene Sanskritta der Natur. HOFFMANN: Vol. 1, p. 46). Essas considerações de "Kreisler" o colocam como precursor da "Metafísica da Música", que Arthur Schopenhaver escreveria mais tarde ${ }^{1}$, além de suas idéias possuírem afinidades com idéias que Richard Wagner viria a expressar.

Os múltiplos talentos de Hoffmann conferiram ao seu texto uma característica singular: uma tendência ao esmaecimento de fronteiras nítidas e estáveis entre os sentidos. Refiro-me à transferência de percepções da esfera de um sentido para outro; à mistura de impressões sensoriais. Hoffmann empregou esse recurso com freqüência, por exemplo, no conto "Cavaleiro Gluck", cuja tradução integral apresento aqui. Ao tentar explicar o modo como um compositor cria música, Hoffmann conferiu ao protagonista as seguintes expressões sinestésicas²: "sons se distinguiam, cintilavam e se enlaçavam em acordes maviosos", ou "melodias afluíam aos cântaros e eu nadava nessa torrente e queria imergir", ou, 
BARBOSA, Maria Aparecida. E. T. A. Hoffmann: tradução da música para a forma...

ainda, "os tons então, como raios de luz, lançavam-se da minha cabeça em direção às flores, que, ávidas, os sugavam".

"Cavaleiro Gluck - uma lembrança do ano de 1809", o primeiro texto do escritor a ser impresso, foi publicado no mencionado Jornal de Música, em 1809. No conto, emocionado com a potência de uma música que sintetizava ódio, amor, desespero e fúria, o narrador (em primeira pessoa) abraçou o músico extraordinário e perguntou: "- $\bigcirc$ que é isso? Quem é o senhor? (...) Solenemente, ele se aproximou de mim, tocou minha mão suavemente e respondeu com um sorriso estranho: - Eu sou o Cavaleiro Gluck!"

O conto se encerra de maneira enigmática, considerando que se trata de "uma lembrança de 1809", isto é, 22 anos após a morte do músico Gluck. Através do conto, Hoffmann presta uma homenagem ao compositor alemão Christoph Willibald Ritter von Gluck: (1714-1787), que postulara a reforma da ópera como gênero. ${ }^{3}$

\section{BIBLIOGRAFIA}

CARPEAUX, Otto Maria. Uma Nova História da Música. Rio de Janeiro: Ediouro, 1999. p. 134.

HOffMANN, E. T. A. E. T. A. Hoffmann Werke (Obras de E. T. A. Hoffmann). Frankfurt am Main: Insel, 1967.

SCHOPENHAUER, Arthur. O Mundo como Vontade e Representação (III Parte). Seleção e tradução de Wolfgang Leo Maar. Assessoria de Rubens Rodrigues Torres Filho. São Paulo: Nova Cultural, 1999.

WitTKOP-MÉNARDEAU, Gabrielle: E. T. A. Hoffmann. Hamburg: Rowohlt, 1966. 


\section{Cavaleiro Gluck ${ }^{4}$ \\ uma lembrança do ano de 1809}

outono tardio em Berlim ainda traz normalmente uns belos dias. $\bigcirc$ sol surge agradável de trás das nuvens e logo a umidade se evapora no ar tépido que sopra as ruas. Então, pode-se ver uma longa fila variada - elegantes, cidadão com esposa e filhos queridos em roupa domingueira, padres, judias, estagiários, prostitutas, professores, faxineiras, dançarinos, oficiais e outros pelas tílias em direção ao Tiergarten. Logo todos os lugares estão ocupados no Klaus e no Weber ${ }^{5}$ : o cheiro de café se espaIha, os elegantes acendem seus charutos, fala-se, discute-se sobre guerra e paz, sobre os sapatos da Madame Bethmann, se eram cinzentos ou verdes da última vez, sobre uma obra de Fichte, o dinheiro difícil e assim por diante, até que tudo começa a fluir numa ária de "Fanchon", onde uma harpa desafinada, alguns violinos destoados, uma flauta tocada a plenos pulmões e um fagote espasmódico torturam a si mesmos e ao ouvinte.

Ao lado da amurada que separa a área do Weber da Heerstraße, há várias mesinhas redondas e cadeiras de jardim, de onde se respira ar fresco, observa-se os passantes, longe do ruído dissonante daquela orquestra amaldiçoada: sentei-me ali, abandonando-me ao leve jogo da minha fantasia que me oferecia figuras amigáveis, com as quais eu conversava sobre Ciência, Arte e tudo que deve ser mais caro ao homem.

Cada vez mais colorida, movimentava-se a massa dos transeuntes diante de mim, mas nada me incomodava, nada conseguia afugentar minha companhia fantástica. Só o indesejável trio de uma valsa bastante infame me tirava do mundo dos sonhos. A voz soprano desafinada de um violino, uma flauta e o ronco grave do fagote contraponto, só isso eu escutava: eles subiam e desciam bem juntos nas oitavas que feriam o ouvido e, involuntaria- 
BARBOSA, Maria Aparecida. E. T. A. Hoffmann: tradução da música para a forma...

mente, como alguém que solta um grito de dor ao se queimar, eu reclamei:

"Que música desenfreada! Que oitava horrível!"

Do meu lado alguém murmurou:

"Destino indesejável! Mais um caçador de oitavas!"

Eu me virei e só então me dou conta de que à minha frente, na mesma mesa, havia se sentado um homem que então me dirigia um olhar fixo, do qual agora meus olhos não podiam mais se desgrudar.

Eu nunca vira uma cabeça, uma figura que me tivessem provocado uma impressão instantânea tão profunda. Um nariz levemente aquilino complementava uma testa larga, com pronunciadas rugas acima das sobrancelhas cinzentas e cerradas, e os olhos faiscavam com um brilho quase jovem e selvagem (o homem tinha uns cinqüenta anos). O queixo de formato suave fazia um contraste estranho com a boca fechada, e um sorriso grotesco, provocado por um movimento de músculos singular nas bochechas flácidas, parecia se sublevar contra a seriedade profunda e melancólica gravada na testa. Somente alguns poucos cachos prateados pousavam atrás das grandes orelhas salientes. Um casaco moderno e bem largo encobria a alta figura esguia.

Tão logo meu olhar o atingiu, ele baixou os olhos e prosseguiu a atividade da qual eu provavelmente o retirara com minha exclamação. Na verdade, ele estava, com visível prazer, despejando tabaco de vários saquinhos numa lata e umedecendo-o com vinho tinto de um quarto de garrafa. A música parara; eu senti necessidade de me dirigir a ele. vel."

"É bom que parem a música", disse-lhe, "estava intolerá-

O velho me olhou rapidamente e esvaziou o último saquinho.

"Seria melhor se não tocassem", tentei mais uma vez entabular uma conversa. 
"O que o senhor acha?"

"Eu não acho nada", disse ele, "o senhor é músico e especialista de profissão..."

"O senhor se engana; não sou um nem outro. Antigamente eu estudava piano e baixo, como parte da boa educação, e, naquela época, disseram-me, entre outras coisas, que nenhum efeito pode ser pior que o do baixo que ultrapassa em oitavas o soprano. Eu assimilei isso como uma verdade e desde então o venho sempre confirmando."

"É mesmo?", interrompeu-me ele, levantando-se e encaminhando-se lento e circunspeto em direção aos músicos, sempre com a mão aberta batendo na testa e olhos virados para o alto, como alguém que força a memória. Eu o vi conversar com os músicos, que ele tratou com conveniente dignidade. Ele retornou ao seu lugar e, mal tinha se sentado, quando os músicos começaram a tocar o prelúdio de "Ifigênia em Áulis".

Com os olhos semicerrados, os braços cruzados apoiados na mesa, ele ouvia o andante; com um leve movimento do pé esquerdo, marcava a entrada das vozes; depois, levantou a cabeça - passou um olhar rápido pelo ambiente -, a mão esquerda espalmada pousava sobre a mesa, como se tocasse um acorde no piano; a mão direita, ele a elevou ao alto: era um maestro, que dava à orquestra os tempos de entrada de cada um - a mão direita caiv e começou o allegro!

Um vermelho ardente queimava-Ihe as bochechas pálidas; as sobrancelhas passeavam juntas pela testa enrugada, um furor inflamou o olhar selvagem com um fogo que apagava gradativamente o sorriso ainda flutuante em torno da boca semi-aberta. Quando ele recostou-se no espaldar da cadeira, as sobrancelhas se levantaram, o tique de músculos nas bochechas recomeçou, os olhos brilhavam, uma dor profunda e íntima se libertou numa volúpia que tomou todas as fibras e vibrou em espasmos - ele 
BARBOSA, Maria Aparecida. E. T. A. Hoffmann: tradução da música para a forma...

respirou do fundo do peito, gotas brotavam-lhe da fronte; ele marcava a entrada dos tutti e de outras passagens mais importantes; sua mão direita não abandonava o compasso; com a esquerda, puxou o lenço para enxugar o rosto. Dessa maneira, vitalizou em carne e osso o esqueleto que aqueles violinos vinham apresentando.

Eu ouvia o lamento suave, melodioso, com que a flauta ascendia, quando a tempestade dos violinos e baixos amainava, e o trovão do tímbalo se calava; eu ouvia os baixos tons vibrantes do violoncelo, do fagote, que enchiam o coração com indizível melancolia; os tutti, então, retornaram; como um gigante majestoso o unissono prosseguia e o abafado lamento se extinguiu, esmagado sob imensos passos.

Prelúdio terminou; o homem deixou ambos os braços caírem e permaneceu sentado com olhos fechados, exausto após o enorme esforço. Sua garrafa estava vazia; enchi seu copo com Burgunda, que eu havia pedido nesse ínterim. Ele suspirou profundamente, parecendo despertar de um sonho. Eu o convidei a beber; ele o fez sem cerimônia e, ao tomar o vinho num gole só, exclamou: tou bem!"

"Eu estou satisfeito com a apresentação! A orquestra se por-

"Sim, senhor," tomei a palavra, "foi feito um pálido contorno de uma obra-prima tocada com cores vivas."

"Diga-me se estou certo: o senhor não é berlinense!"

"De fato, só resido aqui uma vez ou outra!"

"O Burgunda está bom, mas estou sentindo um pouco de frio."

"Então podemos entrar e lá dentro esvaziamos a garrafa."

"Boa idéia. Eu não conheço o senhor, por outro lado o senhor também não me conhece. Não queremos indagar nomes: de vez em quando os nomes incomodam. Eu bebo Burgunda, que 
não estou pagando, nós nos sentimos bem um com o outro e isso é o que importa."

Tudo isso foi dito com uma cordialidade benévola. Nós adentramos o salão; ao se sentar, ele ajeitou o casaco e eu notei surpreso que, sob o mesmo, ele usava uma jaqueta de abas largas bordada na frente, um traje de veludo cobrindo as pernas e uma adaga prateada bem pequenina. Cuidadosamente, ele voltou a abotoar o casaco.

"Por que o senhor me perguntou, se eu era de Berlim?", comecei.

"Porque, nesse caso, eu seria obrigado a deixá-lo."

"Isso soa enigmático."

"Nem um pouco, se eu lhe disser, que, bem, que eu sou um compositor."

"Mas, mesmo assim, eu não o compreendo."

"Então me desculpe pelo que eu disse; vejo que o senhor não entende nada de Berlim e de berlinenses."

Ele se levantou e caminhou vigoroso de um lado para o outro algumas vezes; em seguida, aproximou-se da janela e passou a solfejar, com voz quase inaudível, o canto das sacerdotisas de "Ifigênia em Táuris", marcando aqui e acolá a entrada dos tutti na vidraça da janela. Com estranheza, eu observei que ele fazia certas alterações na melodia, surpreendentes pela força e novidade. Eu o deixei sossegado. Ao terminar, ele voltou ao seu lugar. Bastante impressionado pelo comportamento insólito do homem e pelas manifestações fantásticas do seu raro talento musical, me mantive em silêncio. Após algum tempo, ele perguntou:

"O senhor nunca compôs?"

"Já. Durante um tempo, eu tentei ser artista; tudo o que eu escrevia nos momentos de entusiasmo, todavia, soava-me, mais tarde, fraco e monótono; então acabei desistindo." 
BARBOSA, Maria Aparecida. E. T. A. Hoffmann: tradução da música para a forma...

"O senhor agiu errado. Algumas tentativas fracassadas não provam sua falta de talento. Começamos a aprender música na infância, instados por papai e mamãe; a partir daí, se dedilha e se comete erros; mas, imperceptivelmente, está se apurando o sentido para a melodia. Talvez uma canção semi-esquecida, cantada de outra maneira, seja a primeira composição própria e, esse embrião, penosamente nutrido por forças estranhas, se torna um gigante que absorve e transforma tudo ao redor de si em tutano e sangue!

Ah, como sugerir as mil maneiras de compor! É uma larga Heerstraße, onde todos brincam alegremente, jubilam e gritam: 'Nós somos sagrados! Nós estamos quase no alvo!' Por um portal de marfim se chega ao reino dos sonhos; são poucos os que chegam a vê-lo, menos ainda, os que passam por ele! Assemelha-se a uma aventura. Figuras absurdas vagam de um para o outro lado, embora tenham caráter, cada uma mais forte que a outra. Não é possível vê-las pela Heerstraße, só atrás do portal de marfim se pode encontrá-las.

É difícil retornar desse reino; como no castelo de Alcina, os monstros barram o caminho, tudo se agita, rodopia, muitos se perdem a delirar no reino dos sonhos, se diluem em sonho, eles não projetam mais sombra, se o fizessem, pela sombra tomariam consciência do raio de luz que perpassa o reino; mas só uns poucos, alertas pelo sonho, se elevam e caminham através do reino dos sonhos, eles atingem a verdade, o momento supremo, indizível!

Olhe bem o sol, ele é o trítono do qual os acordes, como estrelas, caem, e nos envolvem com fios luminosos. Crisálidas de fogo, jazemos ali, até que o espírito se eleva ao sol."

Pronunciando as últimas palavras, ele se levantou, olhou ao redor e ergueu a mão. Então voltou a se sentar e bebeu rapidamente o que lhe fora servido. Permaneci sereno, pois não queria confundir aquele homem extraordinário. Finalmente, ele prosseguiu tranqüilamente: 
"Quando eu estive no reino dos sonhos, milhares de aflições e temores me atormentavam! Era noite, me apavoravam as larvas escarnecedoras dos monstros que se precipitavam sobre mim, ora me puxando para as profundezas, ora me erguendo bem alto no ar. Então, raios de luz cruzaram a noite, e os raios de luz eram sons que me abraçavam com doce clareza. Eu despertava do meu martírio e via um olho claro e enorme que mirava um teclado e, à medida que o fazia, sons se distinguiam, cintilavam e se enlaçavam em acordes maviosos, num arranjo que eu jamais pudera imaginar. Melodias afluíam aos cântaros e eu nadava nessa torrente e queria imergir; então o olho me mirava e me mantinha suspenso acima das ondas bramantes."

"Anoitecera novamente, quando dois colossos em armaduras brilhantes se aproximaram de mim: a nota tônica e a quinta! Elas me suspenderam, mas o olho sorria: 'Eu sei o que enche seu peito de melancolia; o suave e meigo Tércio será pisado pelos colossos; você ouvirá a voz terna do jovem, me verá novamente e a minha melodia será sua!'”

Ele se deteve.

"E o senhor reviu o olho?"

"Sim, eu o revi! Durante anos, suspirei no reino dos sonhos, lá... Ah, lá! Eu me sentava num vale magnífico e ouvia atento como as flores cantavam umas para as outras. Só um girassol se mantinha calado e virava triste seu cálice para a terra. Fios invisíveis me seduziram, conduzindo-me até o girassol, que ergueu a cabeça. $O$ cálice da flor abriu-se e o olho brilhou de dentro dele em minha direção. Os tons, então, como raios de luz, estendiamse da minha cabeça em direção às flores que, ávidas, os sugavam. As pétalas do girassol cresciam cada vez mais, dele escorriam lavas que me banhavam, o olho desapareceu, e eu me esvaí no cálice."

Ao pronunciar as últimas palavras, ele deu um salto e caminhou em direção à saída do salão com passos rápidos e juvenis. 
BARBOSA, Maria Aparecida. E. T. A. Hoffmann: tradução da música para a forma...

Depois de esperá-lo inutilmente por algum tempo, decidi retornar à cidade.

Eu já me encontrava perto do Portão de Brandenburg, quando vi na escuridão uma grande figura caminhando ao meu encontro e, logo em seguida, reconheci meu insólito conhecido. FaleiIhe:

"Por que o senhor me deixou tão rapidamente?"

"Ficou muito quente e o Elfo começou a soar."

"Eu não o entendo!"

"Melhor assim."

"Não. Não é melhor assim, pois gostaria muito de compreendê-lo bem."

"O senhor não está ouvindo?"

"Não."

"Passou! Vamos caminhar um pouco. Normalmente não me agrada andar acompanhado; mas o senhor não compõe, nem é berlinense."

"Não consigo compreender as razões da sua aversão aos berlinenses? Nesta cidade, onde a arte é uma prática comum e bem valorizada, penso que um homem com sua índole artística deveria se sentir bem!"

"O senhor se engana! Para minha tortura, estou condenado a errar aqui como uma alma penada num lugar ermo."

"Num lugar ermo, aqui em Berlim?"

"Sim, nenhum espírito afinado se aproxima de mim. Estou só."

"Mas, e os artistas? Os compositores?"

"Fora com eles! Criticam e criticam, aperfeiçoam tudo até o sumo do refinamento, revolvem tudo, apenas para chegar a alguma conclusão mesquinha; em meio à tagarelice sobre arte e sen- 
tido da arte e sei lá mais o quê, não conseguem criar nada. E, se às vezes se encorajam, como se precisassem expor suas idéias à luz do dia, então a frieza medonha mostra a distância do sol: é um trabalho laponês!"6

"Seu julgamento me parece duro demais. Acredito que, pelo menos, as magníficas apresentações teatrais o agradam."

"Eu superei minha resistência e fui, certa vez, ao teatro, a fim de ouvir a ópera do meu jovem amigo... Como é mesmo o nome da ópera? Ora, o mundo inteiro está nessa ópera! Através da multidão colorida de pessoas bem-vestidas, arrastam-se os fantasmas do orco, tudo nela tem voz e som onipotente... Diabos, eu estou falando de 'Don Juan'! No entanto, nem o prelúdio suportei, pois, com o prestissimo completamente sem sentido, não tinha encanto algum; e eu me preparara para a ópera com jejum e orações, porque sei que o Elfo se comove e blasfema com a agitação dessas massas!"

"Se, por um lado, preciso admitir que a obra-prima de Mozart é, em grande parte, negligenciada de forma inexplicável aqui em Berlim, as obras de Gluck, convenhamos, são encenadas com dignidade."

"O senhor acha? Certa vez eu quis ouvir 'Ifigênia em Táuris'. Entrando no teatro, porém, percebi que tocavam o prelúdio de 'Ifigênia em Áulis'. Hum, pensei, me enganei, estão tocando essa 'Ifigênia'! Me surpreendi, quando então começa o andante que abre 'Ifigênia em Táuris' e a tempestade se segue. Só se passaram-se vinte anos! Perdeu-se todo o efeito, a bem calculada exposição da tragédia. Um mar tranqüilo, uma tempestade, os gregos atirados à terra, a ópera é essa! Como? Será que o compositor rabiscou o prelúdio no meio de uma patuscada, de forma que se pode tocá-la como uma peça para trombetas, assim ou assado, ao bel-prazer?"

"Talvez seja mesmo errado. Mas é que se faz de tudo para aperfeiçoar as obras de Gluck." 
BARBOSA, Maria Aparecida. E. T. A. Hoffmann: tradução da música para a forma...

"Ah, sim!", respondeu ele brusco e depois sorriu amargo, cada vez mais amargo.

De repente, deixou-me sozinho e afastou-se caminhando rapidamente. Nada poderia detê-lo. Em instantes tinha sumido, e dias a fio eu o procurei em vão no Tiergarten.

Alguns meses se passaram. Numa tarde chuvosa e fria, eu me demorara num bairro distante da cidade e finalmente voltava a passos largos ao meu apartamento na Friedrichstraße. Tinha de passar pela porta do teatro; a música das trombetas e tímbalos me lembrou de que justamente "Armida", de Gluck, seria apresentada. Eu estava a ponto de entrar, quando atraiu minha atenção um estranho monólogo, próximo à janela de onde se ouve quase perfeitamente a orquestra.

"Agora vem o rei, eles tocam a marcha, tímbalo, por favor, tímbalo! Bem vivo! Isso, isso, eles precisam fazê-lo hoje onze vezes, senão a marcha não terá ímpeto bastante... Hum, ah, maestoso, arrastem-se, criancinhas! Olha só, o figurante com o sapato de lacinho se perdeu... Certo, pela duodécima vez! E sempre marcado pela dominante. Ah, forças eternas, isso não acaba nunca! Agora ele faz o cumprimento... Armida agradece devota... Mais uma vez? Claro, ainda faltam dois soldados! Agora eles passam a recitar aos gritos. Que espírito maldoso agrilhooume aqui?"

"Eu o liberto", disse eu, "venha!"

Rapidamente, saí do Tiergarten levando pelo braço meu estranho conhecido, pois era o próprio que estava ali conversando sozinho. Ele pareceu surpreso e me acompanhou em silêncio. Já estávamos na Friedrichstraße, quando ele parou.

"Eu o conheço", comentou afinal. "O senhor estava no Tiergarten, nós conversamos bastante, eu bebi vinho, fiquei afogueado, depois soou o Elfo por dois dias, padeci muito, mas agora passou!" 
"Alegra-me o acaso de reencontrá-lo. Eu gostaria que nós nos conhecêssemos melhor. Moro não muito longe daqui; que tal se..."

"Não posso, nem devo visitar ninguém!"

"Não, o senhor não vai me escapar; não vou deixá-lo."

"Nesse caso, teremos que caminhar algumas centenas de passos. Mas, o senhor não tencionava ir ao teatro?"

"Eu pretendia ouvir 'Armida', mas agora..."

"O senhor deve ouvir 'Armida' agora! Venha!"

Subimos calados a Friedrichstraße; logo ele adentrou uma perpendicular e eu mal podia acompanhá-lo, tão rápido ele descia a rua. Finalmente paramos em frente a uma casa pouco vistosa. Bateu durante muito tempo, até que alguém abriu a porta. Tateando na escuridão, alcançamos a escada e uma sala no andar superior, cuja porta meu anfitrião trancou com cuidado. Ouvi o barulho de uma porta se abrindo; logo depois ele entrou com uma vela acesa e a visão do insólito revestimento do salão surpreendeu-me.

Cadeiras ricamente adornadas de maneira ultrapassada, um relógio com caixa dourada e um largo e pesado espelho, pendurados à parede, davam à atmosfera a triste aparência do luxo antigo. No centro do salão havia um pequeno piano, sobre o qual estava um grande tinteiro de porcelana e, do lado, algumas folhas de papel. Todavia, um olhar mais rigoroso por esse ambiente de trabalho me convenceu de que há muito tempo nada havia sido composto; pois o papel estava amarelado e havia aranhas sobre o tinteiro.

homem parou em frente a um armário que eu ainda não percebera e, puxando a cortina, deixou à mostra uma série de belos livros encadernados com inscrições douradas: "Orfeo", "Armida, "Alceste", "Ifigênia" e outros, enfim, lá estava a obra completa de Gluck. 
BARBOSA, Maria Aparecida. E. T. A. Hoffmann: tradução da música para a forma...

"O senhor possui a obra completa de Gluck?", perguntei.

Ele não respondeu, mas a boca se crispou num ricto e o movimento muscular nas bochechas proeminentes descompôs o rosto naquele momento, mostrando uma máscara horrível. Com um olhar sombrio pregado em mim, ele retirou um dos livros, era "Armida", e encaminhou-se solenemente ao piano. Eu o abri rapidamente e armei o púlpito dobrado; ele pareceu ver o gesto com prazer. Folheou o livro e - como descrever meu espanto! -, entrevi folhas reticuladas de música sem notas escritas.

Ele começou:

"Agora vou tocar o prelúdio! Folheie o livro de notas no tempo certo!".

Eu prometi fazê-lo e ele então tocou de forma magnífica, como um mestre, completando bem os acordes, o majestoso tempo di marcia, com o prelúdio que se eleva, quase totalmente fiel ao original; mas o allegro possuía somente a idéia essencial de Gluck.

Ele incluía tantas novas mudanças geniais que minha surpresa crescia sem limites. Suas modulações, sobretudo, eram impressionantes, sem jamais se tornarem estridentes. Ele sabia perfilar tantos melodiosos melismas ao fundamento original, que eles pareciam retornar sempre em uma nova, rejuvenescida roupagem. Seu rosto estava inflamado; ora as sobrancelhas se erguiam juntas e uma cólera há muito contida queria explodir com violência, ora os olhos se banhavam em lágrimas de profunda melancolia.

Às vezes ele cantava o tema com uma agradável voz de tenor, enquanto ambas as mãos trabalhavam nos melismas artísticos; nesses momentos ele sabia imitar de uma maneira bastante especial o surdo som dos tímbalos vibrados. Seguindo o movimento dos seus olhos, eu virava as páginas zeloso. Ele terminou o prelúdio e caiu para trás na poltrona, exausto, com os olhos fechados. Logo tornou a si e virando rapidamente as folhas do livro, disse-me com voz indistinta: 
"Tudo isso, meu senhor, eu escrevi ao chegar do reino dos sonhos. Mas eu traí o sagrado com o profano e uma mão gelada tocou meu coração incandescente! Ele não se despedaçou; desde então, porém, sou condenado a vaguear entre os ímpios como um espírito solitário, sem forma, para que ninguém me reconheça, até que o girassol me eleve novamente ao eterno. Ah! Cantemos agora a cena de 'Armida'!"

Então ele cantou a cena final de "Armida", com uma expressão que penetrou fundo na minha alma. Aqui também ele divergia sensivelmente do original; mas ao mesmo tempo sua música transformada se igualava à alta potência da cena de Gluck. Tudo o que ódio, amor, desespero e fúria podem expressar nos registros mais fortes, ele sintetizava grandioso em sons. Sua voz parecia de um jovem, pois do mais profundo e lento andamento ela se erguia à força penetrante. Todas as minhas fibras tremiam, eu estava fora de mim. Quando ele terminou, eu me atirei em seus braços e gritei com voz embargada:

"O que é isso? Quem é o senhor?"

Ele se levantou e me mediu com um olhar grave e intenso; mas quando quis voltar a perguntar, ele saiu pela porta com a luz e me deixou nas trevas. Foram quase quinze minutos; eu me desesperava por revê-lo e procurava abrir as portas, orientando-me pela posição do piano, quando, de súbito, ele retornou com a vela na mão, vestindo um traje de gala bordado, roupas valiosas, a adaga do lado. Eu estava paralisado; solenemente, aproximouse de mim, tocou minha mão suavemente e disse sorrindo estranhamente:

"Eu sou O Cavaleiro Gluck." 
BARBOSA, Maria Aparecida. E. T. A. Hoffmann: tradução da música para a forma...

Eine Erinnerung aus dem Jahre 1809.

Der Spätherbst in Berlin hat gewöhnlich noch einige schöne Tage. Die Sonne tritt freundlich aus dem Gewölk hervor, und schnell verdampft die Nässe in der lauen Luft, welche durch die Straßen weht. Dann sieht man eine lange Reihe, buntgemischt - Elegants, Bürger mit der Hausfrau und den lieben Kleinen in Sonntagskleidern, Geistliche, Jüdinnen, Referendare, Freudenmädchen, Professoren, Putzmacherinnen, Tänzer, Offiziere u. s. w. durch die Linden nach dem Tiergarten ziehen. Bald sind alle Plätze bei Klaus und Weber besetzt; der Mohrrübenkaffee dampft, die Elegants zünden ihre Cigaros an, man spricht, man streitet über Krieg und Frieden, über die Schuhe der Madame Bethmann, ob sie neulich grau oder grün waren, über den geschlossenen Handelsstaat und böse Groschen u. s. w., bis alles in eine Arie aus "Fanchon" zerfließt, womit eine verstimmte Harfe, ein paar nicht gestimmte Violinen, eine lungensüchtige Flöłe und ein spasmatischer Fagott sich und die Zuhörer quälen. Dicht an dem Geländer, welches den Weberschen Bezirk von der Heerstraße trennt, stehen mehrere kleine runde Tische und Gartenstühle; hier atmet man freie Luft, beobachtet die Kommenden und Gehenden, ist entfernt von dem kakophonischen Getöse jenes vermaledeiten Orchesters: da setze ich mich hin, dem leichten Spiel meiner Phantasie mich überlassend, die mir befreundete Gestalten zuführt, mit denen ich über Wissenschaft, über Kunst, über alles, was dem Menschen am teversten sein soll, spreche. Immer bunter und bunter wogt die Masse der Spaziergänger bei mir vorüber, aber nichts stört mich, nichts kann meine phantastische Gesellschaft verscheuchen. Nur das verwünschte Trio eines höchst niederträchtigen Walzers reißt mich aus der Traumwelt. Die kreischende Oberstimme der Violine und Flöte und des Fagotts schnarrenden Grundbaß allein höre ich; sie gehen auf und ab, fest aneinander haltend in Oktaven, die das Ohr zerschneiden, und unwillkürlich wie jemand, den ein brennender Schmerz ergreift, ruf' ich aus: 
"Welche rasende Musik! die abscheulichen Oktaven!" - Neben mir murmelt es:

„Verwünschtes Schicksal! Schon wieder ein Oktaveniäger!“

Ich stehe auf und werde nun erst gewahr, daß, von mir unbemerkt, an demselben Tische ein Mann Platz genommen hat, der seinen Blick starr auf mich richtet, und von dem nun mein Auge nicht wieder loskommen kann.

Nie sah ich einen Kopf, nie eine Gestalt, die so schnell einen so tiefen Eindruck auf mich gemacht hätten. Eine sanfte gebogene Nase schloß sich an eine breite offene Stirn, mit merklichen Erhöhungen über den buschigen halbgrauen Augenbraven, unter denen die Augen mit beinahe wildem, jugendlichem Feuer (der Mann mochte über funfzig sein) hervorblickten. Das weich geformte Kinn stand in seltsamem Kontrast mit dem geschlossenen Munde, und ein skurriles Lächeln, hervorgebracht durch das sonderbare Muskelspiel in den eingefallenen Wangen, schien sich aufzulehnen gegen den tiefen melancholischen Ernst, der auf der Stirn ruhte. Nur wenige grave Löckchen lagen hinter den großen, vom Kopfe abstehenden Ohren. Ein sehr weiter moderner Überrock hüllte die große hagere Gestalt ein. Sowie mein Blick auf den Mann traf, schlug er die Augen nieder und setzte das Geschäft fort, worin ihn mein Ausfruf wahrscheinlich unterbrochen hatte. Er schüttete nämlich aus verschiedenen kleinen Tüten mit sichtbarem Wohlgefallen Tabak in eine vor ihm stehende große Dose und feuchtete ihn mit rotem Wein aus einer Viertelsflasche an. Die Musik hatte aufgehört; ich fühlte die Notwendigkeit, ihn anzureden.

"Es ist gut, daß die Musik schweigt", sagte ich; "das war ja nicht auszuhalten."

Der Alte warf mir einen flüchtigen Blick zu und schüttete die letzte Tüte aus.

"Es wäre besser, daß man gar nicht spielte!" nahm ich nochmals das Wort. "Sind Sie nicht meiner Meinung?" 
BARBOSA, Maria Aparecida. E. T. A. Hoffmann: tradução da música para a forma...

"Ich bin gar keiner Meinung", sagte er. "Sie sind Musiker und Kenner von Profession...."

"Sie irren; beides bin ich nicht. Ich lernte ehemals Klavierspielen und Generalbaß wie eine Sache, die zur guten Erziehung gehört, und da sagte man mir unter anderm, nichts mache einen widrigern Effekt, als wenn der Baß mit der Oberstimme in Oktaven fortschreite. Ich nahm das damals auf Autorität an und habe es nachher immer bewährt gefunden."

"Wirklich?" fiel er mir ein, stand auf und schritt langsam und bedächtig nach den Musikanten hin, indem er öfters, den Blick in die Höhe gerichtet, mit flacher Hand an die Stirn klopfte wie jemand, der irgend eine Erinnerung wecken will. Ich sah ihn mit den Musikanten sprechen, die er mit gebietender Würde behandelte. Er kehrte zurck, und kaum hatte er sich gesetzt, als man die Ouvertüre der "Iphigenia in Aulis" zu spielen begann.

Mit halbgeschlossenen Augen, die verschränkten Arme auf den Tisch gestützt, hörte er das Andante; den linken Fuß leise bewegend, bezeichnete er das Eintreten der Stimmen; jetzt erhob er den Kopf - schnell warf er den Blick umher - die linke Hand mit auseinander gespreizten Fingern ruhte auf dem Tische, als greife er einen Akkord auf dem Flügel, die rechte Hand hob er in die Höhe: es war ein Kapellmeister, der dem Orchester das Eintreten des andern Tempos angibt - die rechte Hand fällt, und das Allegro beginnt! - Eine brennende Röte fliegt über die blassen Wangen; die Augenbraven fahren zusammen auf der gerunzelten Stirn, eine innere Wut entflammt den wilden Blick mit einem Fever, das mehr und mehr das Lächeln wegzehrt, das noch um den halbgeöffneten Mund schwebte. Nun lehnt er sich zurück, hinauf ziehen sich die Augenbrauen, das Muskelspiel auf den Wangen kehrt wieder, die Augen erglänzen, ein tiefer innerer Schmerz löst sich auf in Wollust, die alle Fibern ergreift und krampfhaft erschüttert - tief aus der Brust zieht er den Atem, Tropfen stehen auf der Stirn; er deutet das Eintreten des Tutti und andere Hauptstellen an; seine rechte Hand 
verläßt den Takt nicht, mit der linken holt er sein Tuch hervor und fährt damit über das Gesicht. - So belebte er das Skelett, welches jene paar Violinen von der Ouvertüre gaben, mit Fleisch und Farben. Ich hörte die sanfte, schmelzende Klage, womit die Flöte emporsteigt, wenn der Sturm der Violinen und Bässe ausgetobt hat und der Donner der Pauken schweigt; ich hörte die leise anschlagenden Töne der Violoncelle, des Fagotts, die das Herz mit unnennbarer Wehmut erfüllen; das Tutti kehrt wieder, wie ein Riese hehr und groß schreitet das Unisono fort, die dumpfe Klage erstirbt unter seinen zermalmenden Tritten.

Die Ouvertüre war geendigt; der Mann ließ beide Arme herabsinken und saß mit geschlossenen Augen da wie jemand, den eine übergroße Anstrengung entkräftet hat. Seine Flasche war leer; ich füllte sein Glas mit Burgunder, den ich mir unterdessen hatte geben lassen. Er seufzte tief auf, er schien aus einem Traume zu erwachen. Ich nötigte ihn zum Trinken; er that es ohne Umstände, und indem er das volle Glas mit einem Zuge hinunterstürzte, rief er aus: "Ich bin mit der Aufführung zufrieden! das Orchester hielt sich brav!"

"Und doch", nahm ich das Wort, "doch wurden nur schwache Umrisse eines mit lebendigen Farben ausgeführten Meisterwerks gegeben."

"Urteile ich richtig? - Sie sind kein Berliner!"

"Ganz richtig; nur abwechselnd halte ich mich hier auf."

"Der Burgunder ist gut; aber es wird kalt."

"So lassen Sie uns ins Zimmer gehen und dort die Flasche leeren."

"Ein guter Vorschlag. - Ich kenne Sie nicht, dafür kennen Sie mich aber auch nicht. Wir wollen uns unsre Namen nicht abfragen; Namen sind zuweilen lästig. Ich trinke Burgunder, er kostet mich nichts, wir befinden uns wohl bei einander, und damit gut."

Er sagte dies alles mit gutmütiger Herzlichkeit. Wir waren ins Zimmer getreten; als er sich setzte, schlug er den Überrock aus- 
BARBOSA, Maria Aparecida. E. T. A. Hoffmann: tradução da música para a forma...

einander, und ich bemerkte mit Verwunderung, daß er unter demselben eine gestickte Weste mit langen Schößen, schwarzsamtne Beinkleider und einen ganz kleinen silbernen Degen trug. Er knöpfte den Rock sorfgältig wieder zu.

"Warum fragten Sie mich, ob ich ein Berliner sei?" begann ich.

„Weil ich in diesem Falle genötigł gewesen wäre, Sie zu verlassen."

"Das klingt rätselhaft."

"Nicht im mindesten, sobald ich Ihnen sage, daß ich - nun, daß ich ein Komponist bin."

"Noch immer errate ich Sie nicht."

"So verzeihen Sie meinen Ausruf vorhin; denn ich sehe, Sie verstehen sich ganz und gar nicht auf Berlin und auf Berliner."

Er stand auf und ging einigemal heftig auf und ab; dann trat er ans Fenster und sang kaum vernehmlich den Chor der Priesterinnen aus der "Iphigenia in Tauris", indem er dann und wann bei dem Eintreten der Tutti an die Fensterscheiben klopfte. Mit Verwundern bemerkte ich, daß er gewisse andere Wendungen der Melodien nahm, die durch Kraft und Neuheit frappierten. Ich ließ ihn gewähren. Er hatte geendigt und kehrte zurück zu seinem Sitz. Ganz ergriffen von des Mannes sonderbarem Benehmen und den phantastischen Äußerungen eines seltenen musikalischen Talents, schwieg ich. Nach einer Weile fing er an:

"Haben Sie nie komponiert?"

"Ja, ich habe mich in der Kunst versucht; nur fand ich alles, was ich, wie ich mich dünkte, in Augenblicken der Begeisterung geschrieben hatte, nachher matt und langweilig; da ließ ich's denn bleiben."

"Sie haben Unrecht gethan; denn schon, daß Sie eigne Versuche verwarfen, ist kein übles Zeichen Ihres Talents. Man lernt 
Musik als Knabe, weil's Papa und Mama so haben wollen; nun wird darauf los geklimpert und gegeigt; aber unvermerkt wird der Sinn empfänglicher für Melodie. Vielleicht war das halb vergessene Thema eines Liedchens, welches man nun anders sang, der erste eigne Gedanke, und dieser Embryo, mühsam genährt von fremden Kräften, genas zum Riesen, der alles um sich her aufzehrte und in sein Mark und Blut verwandelte! - Ha, wie ist es möglich, die tausenderlei Arten, wie man zum Komponieren kommt, auch nur anzudeuten? - Es ist eine breite Heerstraße, da tummeln sich alle herum und jauchzen und schreien: Wir sind Geweihte! wir sind am Ziel!' - Durchs elfenbeinerne Thor kommt man ins Reich der Träume; wenige sehen das Thor einmal? Noch wenigere gehen durch! - Abenteuerlich sieht es hier aus. Tolle Gestalten schweben hin und her, aber sie haben Charakter - eine mehr wie die andere. Sie lassen sich auf der Heerstraße nicht sehen; nur hinter dem elfenbeinernen Thor sind sie zu finden. Es ist schwer, aus diesem Reiche zu kommen; wie vor Alzinens Burg versperren die Ungeheuer den Weg - es wirbelt - es dreht sich - viele verträumen den Traum im Reiche der Träume - sie zerfließen im Traum - sie werfen keinen Schatten mehr, sonst würden sie am Schatten gewahr werden den Strahl, der durch dies Reich fährt; aber nur wenige, erweckt aus dem Traume, steigen empor und schreiten durch das Reich der Träume - sie kommen zur Wahrheit - der höchste Moment ist da: die Berührung mit dem Ewigen, Unaussprechlichen! - Schaut die Sonne an, sie ist der Dreiklang, aus dem die Akkorde, Sternen gleich, herabschießen und euch mit Feuerfaden umspinnen. - Verpuppt im Fever liegt ihr da, bis sich Psyche emporschwingt in die Sonne."

Bei den letzten Worten war er aufgesprungen, warf den Blick, warf die Hand in die Höhe. Dann setzte er sich wieder und leerte schnell das ihm eingeschenkte Glas. Es entstand eine Stille, die ich nicht unterbrechen mochte, um den außerordentlichen Mann nicht aus dem Geleise zu bringen. Endlich fuhr er beruhigter fort: 
BARBOSA, Maria Aparecida. E. T. A. Hoffmann: tradução da música para a forma...

"Als ich im Reich der Träume war, folterten mich tausend Schmerzen und Ängste! Nacht war's, und mich schreckten die grinsenden Larven der Ungehever, welche auf mich einstürmten und mich bald in den Abgrund des Meeres versenkten, bald hoch in die Lüfte emporhoben. Da fuhren Lichtstrahlen durch die Nacht, und die Lichtstrahlen waren Töne, welche mich umfingen mit lieblicher Klarheit. - Ich erwachte von meinen Schmerzen und sah ein großes helles Auge, das blickte in eine Orgel, und wie es blickte, gingen Töne hervor und schimmerten und umschlangen sich in herrlichen Akkorden, wie ich sie nie gedacht hatte. Melodien stürmten auf und nieder, und ich schwamm in diesem Strom und wollte untergehen: da blickte das Auge mich an und hielt mich empor über den brausenden Wellen. - Nacht wurde es wieder, da traten zwei Kolosse in glänzenden Harnischen auf mich zu: Grundton und Quinte! sie rissen mich empor, aber das Auge lächelte: ,Ich weiß, was deine Brust mit Sehnsucht erfüllt; der sanfte, weiche Jüngling, Terz, wird unter die Kolossen treten; du wirst seine süße Stimme hören, mich wiedersehen, und meine Melodien werden dein sein. "“

Er hielt inne.

"Und Sie sahen das Auge wieder?"

„Ja, ich sah es wieder! - Jahrelang seufzt ${ }^{\prime}$ ich im Reich der Träume - da - ja da! Ich saß in einem herrlichen Th al und hörte zu, wie die Blumen miteinander sangen. Nur eine Sonnenblume schwieg und neigte traurig den geschlossenen Kelch zur Erde. Unsichtbare Bande zogen mich hin zu ihr - sie hob ihr Haupt - der Kelch schloß sich auf, und aus ihm strahlte mir das Auge entgegen. Nun zogen die Töne wie Lichtstrahlen aus meinem Haupte zu den Blumen, die begierig sie einsogen. Größer und größer wurden der Sonnenblume Blätter - Gluten strömten aus ihnen hervor - sie umschlossen mich - das Auge war verschwunden und ich im Kelche."

Bei den letzten Worten sprang er auf und eilte mit raschen, jugendlichen Schritten zum Zimmer hinaus. Vergebens wartete ich 
auf seine Zurückkunft; ich beschloß daher, nach der Stadt zu gehen.

Schon war ich in der Nähe des Brandenburger Thores, als ich in der Dunkelheit eine lange Figur hinschreiten sah und alsbald meinen Sonderling wiedererkannte. Ich redete ihn an:

"Warum haben Sie mich so schnell verlassen?"

"Es wurde zu heiß, und der Euphon fing an zu klingen."

"Ich verstehe Sie nicht!"

"Desto besser."

"Desto schlimmer, denn ich mchte Sie gern ganz verstehen."

"Hören Sie denn nichts?"

"Nein."

- „Es ist vorüber! - Lassen Sie uns gehen! Ich liebe sonst nicht eben die Gesellschaft; aber - Sie komponieren nicht - Sie sind kein Berliner."

"ICh kann nicht ergründen, was Sie so gegen die Berliner einnimt? Hier, wo die Kunst geachtet und in hohem Maße ausgeübt wird, sollt' ich meinen, müßte einem Manne von Ihrem künstlerischen Geiste wohl sein!"

"Sie irren! - Zu meiner Qual bin ich verdammt, hier wie ein abgeschriebener Geist im öden Raume umherzuirren."

"Im öden Raume, hier, in Berlin?"

"Ja, öde ist's um mich her, denn kein verwandter Geist tritt auf mich zu. Ich stehe allein."

„Aber die Künstler! die Komponisten!"

„Weg damit! Sie kritteln und kritteln - verfeinern alles bis zur feinsten Meßlichkeit; wühlen alles durch, um nur einen armseligen Gedanken zu finden; über dem Schwatzen von Kunst, von Kunstsinn, und was weiß ich - können sie nicht zum Schaffen kommen, und wird ihnen einmal so zu Mute, als wenn sie ein 
BARBOSA, Maria Aparecida. E. T. A. Hoffmann: tradução da música para a forma...

paar Gedanken ans Tageslicht befördern müßten, so zeigł die furchtbare Kälte ihre weite Entfernung von der Sonne - es ist lappländische Arbeit!"

"Ihr Urteil scheint mir viel zu hart. Wenigstens müssen Sie die herrlichen Aufführungen im Theater befriedigen."

"Ich hatte es über mich gewonnen, einmal wieder ins Theater zu gehen, um meines jungen Freundes Oper zu hören - wie heißt sie gleich? - Ha, die ganze Welt ist in dieser Oper! Durch das bunte Gewühl geputzter Menschen ziehen die Geister des Orkus alles hat hier Stimme und allmächtigen Klang - Teufel, ich meine ja ,Don Juan!' - Aber nicht die Ouvertüre, welche Prestissimo ohne Sinn und Verstand abgesprudelt wurde, konnt' ich überstehen; und ich hatte mich bereitet dazu durch Fasten und Gebet, weil ich weiß, daß der Euphon von diesen Massen viel zu sehr bewegt wird und unrein anspricht!"

"Wenn ich auch eingestehen muß, daß Mozarts Meisterwerke größtenteils auf eine kaum erklärliche Weise hier vernachlässigt werden, so erfreuen sich doch Glucks Werke gewiß einer würdigen Darstellung."

"Meinen Sie? - Ich wollte einmal ,Iphigenia in Tauris' hören. Als ich ins Theater trete, höre ich, daß man die Ouvertüre der ,Iphigenia in Aulis' spielt. Hm - denke ich, ein Irrtum; man gibt diese Iphigenia! Ich erstaune, als nun das Andante eintritt, womit die, Iphigenia in Tauris' anfängt, und der Sturm folgt. Zwanzig Jahre liegen dazwischen! Die ganze Wirkung, die ganze wohlberechnete Exposition des Traverspiels geht verloren. Ein stilles Meer - ein Sturm - die Griechen werden ans Land geworfen, die Oper ist da! Wie? hat der Komponist die Ouvertüre ins Gelag hinein geschrieben, daß man sie wie ein Trompeterstückchen abblasen kann, wie und wo man will?"

"Ich gestehe den Mißgriff ein. Indessen, man thut doch alles, um Glucks Werke zu heben." 
„Ei ja!" sagte er kurz und lächelte dann bitter und immer bitterer. Plötzlich fuhr er auf, und nichts vermochte ihn aufzuhalten. Er war im Augenblicke wie verschwunden, und mehrere Tage hintereinander suchte ich ihn im Tiergarten vergebens.

Einige Monate waren vergangen, als ich an einem kalten regnichten Abende mich in einem entfernten Teile der Stadt verspätet hatte und nun mach meiner Wohnung in der Friedrichsstraße eilte. Ich mußte bei dem Theater vorbei; die rauschende Musik, Trompeten und Pauken erinnerten mich, daß gerade Glucks "Armida" gegeben wurde, und ich war im Begriff, hineinzugehen, als ein sonderbares Selbstgespräch dicht an den Fenstern, wo man fast jeden Ton des Orchesters hört, meine Aufmerksamkeit erregte.

"Jetzt kömmt der König - sie spielen den Marsch - o paukt, paukt nur zu! - 's ist recht munter! ja, ja, sie müssen ihn heute elfmal machen - der Zug hat sonst nicht Zug genug - Ha ha maestoso - schleppt euch, Kindercheen. - Sieh, da bleibt ein Figurant mit der Schuhschleife hängen. - Richtig, zum zwölftenmal! und immer auf die Dominante hinausgeschlagen. - $O$ ihr ewigen Mächte, das endet nimmer! Jetzt macht er sein Kompliment - Armida dankt ergebenst. - Noch einmal? - Richtig, es fehlen noch zwei Soldaten! Jetz† wird ins Rezitativ hineingepoltert. - Welcher böse Geist hat mich hier festgebannt?"

"Der Bann ist gelöst", rief ich. "Kommen Sie!"

Ich faßte meinen Sonderling aus dem Tiergarten - denn niemand anders war der Selbstredner - rasch beim Arm und zog ihn mit mir fort. Er schien überrascht und folgte mir schweigend. Schon waren wir in der Friedrichsstraße, als er plötzlich stillstand. "Ich kenne Sie", sagte er. "Sie waren im Tiergarten - wir sprachen viel ich habe Wein getrunken - habe mich erhitzt - nachher klang der Euphon zwei Tage hindurch - ich habe viel ausgestanden - es ist vorüber!" 
BARBOSA, Maria Aparecida. E. T. A. Hoffmann: tradução da música para a forma...

"Ich freve mich, daß der Zufall Sie mir wieder zugeführt hat. Lassen Sie uns näher miteinander bekannt werden! Nicht weit von hier wohne ich; wie wär' es -“

"Ich kann und darf zu niemand gehen."

"Nein, Sie entkommen mir nicht; ich gehe mit Ihnen."

"So werden Sie noch ein paar hundert Schritte mit mir laufen müssen. Aber Sie wollten ja ins Theater?"

"Ich wollte ,Armida' hören, aber nun - "

"Sie sollen jetz† ,Armida' hören! Kommen Sie!"

Schweigend gingen wir die Friedrichsstraße hinauf; rasch bog er in eine Querstraße ein, und kaum vermochte ich ihm zu folgen, so schnell lief er die Straße hinab, bis er endlich vor einem unansehnlichen Hause stillstand. Ziemlich lange hatte er gepocht, als man endlich öffnete. Im Finstern tappend, erreichten wir die Treppe und ein Zimmer im oberen Stock, dessen Thüre mein Führer sorgfältig verschloß. Ich hörte noch eine Thüre öffnen; bald darauf trat er mit einem angezündeten Lichte hinein, und der Anblick des sonderbar ausstaffierten Zimmers überraschte mich nicht wenig. Altmodisch reichverzierte Stühle, eine Wanduhr mit vergoldetem Gehäuse und ein breiter, schwerfälliger Spiegel gaben dem Ganzen das düstere Ansehn veriährter Pracht. In der Mitte stand ein kleines Klavier, auf demselben ein großes Tintenfaß von Porzellan, und daneben lagen einige Bogen rastriertes Papier. Ein schärferer Blick auf diese Vorrichtung zum Komponieren überzeugte mich jedoch, daß seit langer Zeit nichts geschrieben sein mußte; denn ganz vergelbt war das Papier, und dickes Spinnengewebe überzog das Tintenfaß. Der Mann trat vor einen Schrank in der Ecke des Zimmers, den ich noch nicht bemerkt hatte, und als er den Vorhang wegzog, wurde ich eine Reihe schön gebundener Bücher gewahr mit goldnen Aufschriften: "Orfeo", "Armida", "Alceste", "Iphigenia" u. s. w., kurz, Glucks Meisterwerke sah ich beisammen stehen. 
"Sie besitzen Glucks sämtliche Werke?" rief ich.

Er antwortete nicht, aber zum krampfhaften Lächeln verzog sich der Mund, und das Muskelspiel in den eingefallenen Backen verzerrte im Augenblick das Gesicht zur schauerlichen Maske. Starr den düstern Blick auf mich gerichtet, ergriff er eins der Bücher - es war "Armida" - und schritt feierlich zum Klavier hin. Ich öffnete es schnell und stellte den zusammengelegten Pult auf; er schien das gern zu sehen. Er schlug das Buch auf, und - wer schildert mein Erstaunen? - ich erblickte rastrierte Blätter, aber mit keiner Note beschrieben.

Er begann: "Jetz† werde ich die Ouvertüre spielen! Wenden Sie die Blätter um, und zur rechten Zeit!" Ich versprach das, und nun spielte er herrlich und meisterhaft mit vollgriffigen Akkorden das majestätische Tempo di Marcia, womit die Ouvertüre anhebt, fast ganz dem Original getreu; aber das Allegro war nur mit Glucks Hauptgedanken durchflochten. Er brachte so viele neue geniale Wendungen hinein, daß mein Erstaunen immer wuchs. Vorzüglich waren seine Modulationen frappant, ohne grell zu werden, und er wußte den einfachen Hauptgedanken so viele melodiöse Melismen anzureihen, daß jene immer in never, veriüngter Gestalt wiederzukehren schienen. Sein Gesicht glühte; bald zogen sich die Augenbrauen zusammen, und ein lang verhaltener Zorn wollte gewaltsam losbrechen, bald schwamm das Auge in Thränen tiefer Wehmut. Zuweilen sang er, wenn beide Hände in künstlichen Melismen arbeiteten, das Thema mit einer angenehmen Tenorstimme; dann wußte er auf eine ganz besondere Weise mit der Stimme den dumpfen Ton der anschlagenden Pauke nachzuahmen. Ich wandte die Blätter fleißig um, indem ich seine Blicke verfolgte. Die Ouvertüre war geendet, und er fiel erschöpft mit geschlossenen Augen in den Lehnstuhl zurück. Bald raffte er sich aber wieder auf, und indem er hastig mehrere leere Blätter des Buchs umschlug, sagte er mit dumpfer Stimme:

"Alles dieses, mein Herr, habe ich geschrieben, als ich aus dem Reich der Träume kam. Aber ich verriet Unheiligen das Heili- 
ge, und eine eiskalte Hand faßte in dies glühende Herz! Es brach nicht; da wurde ich verdammt, zu wandeln unter den Unheiligen wie ein abgeschiedener Geist - gestaltlos, damit mich niemand kenne, bis mich die Sonnenblume wieder emporhebt zu dem Ewigen. - Ha - jetzt lassen Sie uns Armidens Szene singen!“

Nun sang er die Schlußszene der "Armida" mit einem Ausdruck, der mein Innerstes durchdrang. Auch hier wich er merklich von dem eigentlichen Originale ab; aber seine veränderte Musik war die Glucksche Szene gleichsam in höherer Potenz. Alles, was Haß, Liebe, Verzweiflung, Raserei in den sträksten Zügen ausdrücken kann, faßte er gewaltig in Töne zusammen. Seine Stimme schien die eines Jünglings, denn von tiefer Dumptheit schwoll sie empor zur durchdringenden Stärke. Alle meine Fibern zitterten - ich war außer mir. Als er geendet hatte, warf ich mich ihm in die Arme und rief mit gepreßter Stimme: "Was ist das? wer sind Sie?"

Er stand auf und maß mich mit ernstem, durchdringendem Blick; doch als ich weiter fragen wollte, war er mit dem Lichte durch die Thüre entwichen und hatte mich im Finstern gelassen. Es hatte beinahe eine Viertelstunde gedavert; ich verzweifelte, ihn wiederzusehen, und suchte, durch den Stand des Klaviers orientiert, die Thüre zu öffnen, als er plötzlich in einem gestickten Galakleide, reicher Weste, den Degen an der Seite, mit dem Lichte in der Hand hereintrat.

Ich erstarrte; feierlich kam er auf mich zu, faßte mich sanft bei der Hand und sagte, sonderbar lächelnd: "Ich bin der Ritter Gluck!"

1 "A música se diferencia de todas as outras artes por não ser reprodução do fenômeno, ou mais corretamente, da objetividade adequada da vontade, mas cópia imediata da vontade ela própria, apresentando portanto para tudo o que é físico no mundo, o metafísico, para todo fenômeno, a coisa-em-si." Schopenhaver, Arthur. O Mundo como Vontade e Represen- 
tação (III Parte). Seleção e tradução de Wolfgang Leo Maar. Assessoria de Rubens Rodrigues Torres Filho. São Paulo: Nova Cultural, 1999. p. 110.

2 Na fisiologia, sinestesia é um termo usado para descrever uma sensação em uma parte do corpo quando outra parte é estimulada; e, em psicologia, para indicar quando um estímulo sensorial (como cor) evoca outro sentido (cheiro).

3 Carpeaux explica o programa de Gluck: "os enredos mitológicos deveriam ser da maior simplicidade e de mais forte efeito trágico. Eliminar-se-iam a vazia pompa barroca, os arabescos do bel canto exibicionista dos virtuoses da garganta." Carpeaux,Otto Maria: Uma Nova História da Música Rio de Janeiro: Ediouro, 1999. p. 134. A música de Gluck teria a simplicidade do novo classicismo, inaugurado pelo contemporâneo Winckelmann que, por sua vez, estudava a arte a partir da escultura grega.

4 "Ritter Gluck". In: Fantasiestücke in Callots Manier - Blätter aus dem Tagebuche eines reisenden Enthusiasten (Quadros à maneira de Callot - do diário de um viajante entusiasta). In: E. T. A. Hoffmann Werke. Volume I, p. 9. Tradução integral do conto: Maria Aparecida Barbosa.

5 Klaus e Weber são cafés localizados no bairro central de Berlim denominado Tiergarten onde ficam também as ruas Heerstraße e Friedrichstraße, mencionadas um pouco adiante. (Nota da tradutora).

6 Lappländische Arbeit: creio que o atributo pode ser lido na acepção de frio, como uma referência à temperatura da região denominada Lapônia, localizada na Finlândia, ou no sentido de trivial, superficial, néscio, como a expressão läppisch. (N.T.)

\section{GlossÁRIO}

Madame Bethmann: Friederike Bethmann-Unzelmann (1760-1815) era considerada uma grande atriz romântica por causa de sua interpretação impregnada de sentimentalismo.

Fanchon: "Fanchon oder das Leiermädchen" (1799), (Fancho ou a Menina do Realejo), uma canção popular da época, de Friedrich Heinrich Himmel (1765-1814), conforme libreto de Kotzebue.

Ifigênia em Áulis, Ifigênia em Táuris: óperas de Gluck, respectivamente, de 1774 e 1779.

Castelo de Alcina: do épico de Ariosto (1474-1533) "Orlando Furioso". (A tradução brasileira é muito acurada: de Pedro Garcez Ghirardi. CotiaSP: Ateliê Editoral, 2002). Rogério é detido em frente ao castelo da feiticeira Alcina por monstros, que ele, todavia, derrota (Canto 6, estrofes 61-67).

Elfo: significado incerto; refere-se à força criadora do músico, ou à uma alucinação do herói. 
BARBOSA, Maria Aparecida. E. T. A. Hoffmann: tradução da música para a forma...

Eu superei minha resistência: nas próximas passagens, Hoffmann criti$\mathrm{ca}$, de fato, falhas da ópera berlinense.

"Don Juan": a ópera de Mozart foi encenada no segundo semestre de 1807, em Berlim, apenas duas vezes.

à Friedrichstraße: durante sua segunda permanência em Berlim, Hoffmann morou à Friedrichstraße 179.

Armida: essa ópera composta em 1777 foi apresentada três vezes em Berlim, em 1808.

Agora vem o rei: "Armida" I, 2.

Tempo di marcia: tempo de marcha.

Modulações: passagens de um tom ao outro.

Melismas: adornos melódicos. 